3

4

5

6

7

\title{
8 Activity levels of preterm children at seven years of age
}

9

\section{REVIEWED BY}

11 Benjamin F Mentiplay, $\mathrm{PhD}$

Murdoch Children's Research Institute

benjamin.mentiplay@mcri.edu.au

Tara L FitzGerald, BPhysio(Hons)

Murdoch Children's Research Institute

17

tara.fitzgerald@mcri.edu.au

Alicia J Spittle, $\mathrm{PhD}$

University of Melbourne

aspittle@unimelb.edu.au

\section{Corresponding Author:}

This is the author manuscript accepted for publication and has undergone full peer review but has not been through the copyediting, typesetting, pagination and proofreading process, which may lead to differences between this version and the Version of Record. Please cite this article as doi: 10.1111/apa.14228

This article is protected by copyright. All rights reserved 
Benjamin F Mentiplay

25

Victorian Infant Brain Studies, Murdoch Children's Research Institute

The Royal Children's Hospital

50 Flemington Rd, Parkville VIC 3052

AUSTRALIA

Phone: +61400801627

Email: benjamin.mentiplay@mcri.edu.au

\section{MANUSCRIPT CITATION}

Lowe J, Watkins WJ, Kotecha SJ, Kotecha S. Physical activity and sedentary behavior in preterm-born 7-year old children. PLoS ONE 2016; 11(5): e0155229. PMID 27168339.
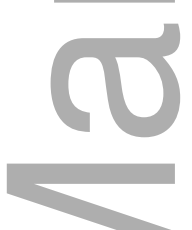

\section{COMMENTARY}

Children born very preterm ( $<32$ weeks' gestation) are at a higher risk of various difficulties compared with children born at term, such as increased motor impairment (1). Physical activity is important for the general population, with physical activity often included in healthy living guidelines for children. Physical activity, when measured with questionnaires, has been shown to be reduced in adolescents and young adults who were born very preterm $(2,3)$. Interestingly, when measured objectively with accelerometry, physical activity levels are similar in adolescents and adults born preterm compared with their term born peers (4-7). However, there appears to be little research in younger children born preterm using objective measures of physical activity. Therefore, Lowe and colleagues studied seven-year-old children who were born preterm to examine levels of physical activity and sedentary behaviour compared with term born children (8).

This large-scale cohort study of over 6,000 children across the United Kingdom born across the gestational age spectrum (8), found seven-year-old boys born very preterm spent 
significantly less time in moderate to vigorous physical activity (MVPA) compared with term born boys. Trends were also shown toward reduced total physical activity and increased sedentary time in boys born very preterm, although this association was not significant in fully adjusted models. Lowe and colleagues also found that this association was not mediated by respiratory symptoms, and they also found no association between gestational age and any physical activity measure in girls.

Participants in this study showed high levels of MVPA, with many children meeting or exceeding recommended physical activity guidelines. In contrast, previous studies have shown preterm and term born children fail to meet the recommended guidelines $(4,5)$. Comparison of physical activity research is problematic due to the differing methods between studies (e.g.various types of accelerometers, data collection epochs and cut-points for intensity definitions). The monitor used by Lowe and colleagues was an Actigraph uniaxial accelerometer worn around the hip, with previous studies examining preterm physical activity using both the same (4-6) and different accelerometers (7). Further highlighting the disparities between physical activity research methodology, the cut-point used by Lowe and colleagues for MVPA differs with previous research, which may have led to a potential overestimation (or underestimation) of MVPA levels. Thus, caution is needed when considering the results of this study compared to previous physical activity research.

In conclusion, this cohort study provides informative and objective data on the physical activity levels of preterm children at seven-years of age, with boys born very preterm having lower physical activity levels compared with term born children. Recent research has examined the factors associated with physical activity in adolescents born preterm (9) however little is currently known in younger children. As this study found that respiratory symptoms did not mediate the association between gestational age and physical activity in seven-year-old children, further work in younger children is needed to examine what factors are associated with physical activity to inform the design of early intervention strategies aimed to improve physical activity in this potentially at-risk population.

\section{URL TO THE FULL REVIEW ON THE EBNEO WEBSITE:}


Ms. FitzGerald's PhD candidature is supported by The University of Melbourne via The Australian Government Research Training Program Scholarship and the Centre of Research Excellence in Newborn Medicine.

A/Prof Spittle is supported by a Career Development Fellowship from the National Health and Medical Research Council.

$\square$

\section{CONFLICTS OF INTEREST}

None.

\section{REFERENCES}

1. de Kieviet JF, Piek JP, Aarnoudse-Moens CS, Oosterlaan J. Motor development in very preterm and very low-birth-weight children from birth to adolescence: a metaanalysis. JAMA 2009; 302: 2235-42.

2. Tikanmäki M, Kaseva N, Tammelin T, Sipola-Leppänen M, Matinolli HM, Eriksson JG, et al. Leisure time physical activity in young adults born preterm. $J$ Pediatr 2017; 189: $135-42$.

3. Dahan-Oliel N, Mazer B, Majnemer A. Preterm birth and leisure participation: a synthesis of the literature. Res Dev Disabil 2012; 33: 1211-20.

4. Lowe J, Watkins WJ, Kotecha SJ, Edwards MO, Henderson AJ, Kotecha S. Physical activity in school-age children born preterm. $J$ Pediatr 2015; 166: 877-83.

5. Welsh L, Kirkby J, Lum S, Odendaal D, Marlow N, Derrick G, et al. The EPICure study: maximal exercise and physical activity in school children born extremely preterm. Thorax 2010; 65: 165-72.

6. Tikanmäki M, Tammelin T, Kaseva N, Sipola-Leppänen M, Matinolli HM, Hakonen $\mathrm{H}$, et al. Objectively measured physical activity and sedentary time in young adults born preterm: the ESTER study. Pediatr Res 2017; 81: 550-5.

7. Kaseva N, Martikainen S, Tammelin T, Hovi P, Järvenpää AL, Andersson S, et al. Objectively measured physical activity in young adults born preterm at very low birth weight. J Pediatr 2015; 166: 474-6. 
8. Lowe J, Watkins WJ, Kotecha SJ, Kotecha S. Physical activity and sedentary behavior in preterm-born 7-year old children. PLOS ONE 2016; 11: e0155229.

9. Proulx K, Majnemer A, Dahan-Oliel N, Mazer B, Nadeau L, Vanier K, et al. Factors associated with moderate to vigorous physical activity in adolescents born preterm. Pediatr Exerc Sci 2017; 29: 260-7.

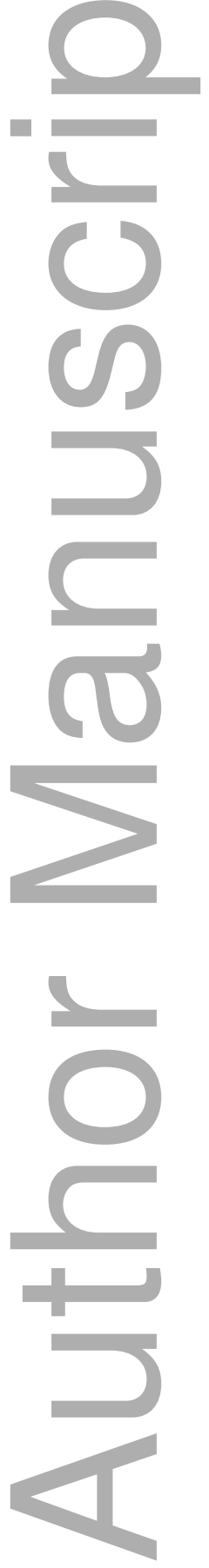




\section{University Library}

\section{- M M I N E R VA A gateway to Melbourne's research publications}

Minerva Access is the Institutional Repository of The University of Melbourne

Author/s:

Mentiplay, BF;FitzGerald, TL;Spittle, AJ

Title:

Activity levels of preterm children at seven years of age

Date:

2018-05-01

Citation:

Mentiplay, B. F., FitzGerald, T. L. \& Spittle, A. J. (2018). Activity levels of preterm children at seven years of age. ACTA PAEDIATRICA, 107 (5), pp.905-905. https://doi.org/10.1111/ apa.14228.

Persistent Link:

http://hdl.handle.net/11343/283579 